UDC $62-752+62-755: 621.634$

DOI: $10.15587 / 1729-4061.2016 .79970$
Сформульовано емпіричний критерій настання автобалансування для ротора, що балансується пасивними автобалансирами. Критерій дозволяє визначати діапазони ивидкостей обертання ротора, на яких настає автобалансування. Він застосовний для жорстких роторів на піддатливих опорах $i$ для гнучких роторів при будь-якій кількості пасивних автобалансирів будь-якого типу. рію для ротора з нерухомою точкою

Ключові слова: ротор, автобалансир, автобалансування, критерій настання автобалансування, основний рух, стійкicmb pyxy

Сформулирован эмпирический критерий наступления автобалансировки для ротора, уравновешиваемого пассивными автобалансирами. Критерий позволяет определять диапазоны скоростей вращения ротора, на которых наступает автобалансировка. Он применим для жестких роторов на податливых опорах и для гибких роторов при любом количестве пассивных автобалансиров любого типа. Приведен пример применения критерия для ротора с неподвижной точкой

Ключевые слова: ротор, автобалансир, автобалансировка, критерий наступления автобалансировки, основное движение, устойчивость движения Наведений приклад застосування крите-

\section{EMPIRICAL CRITERION FOR THE OCCURRENCE OF AUTO-BALANCING AND ITS APPLICATION FOR AXISYMMETRIC ROTOR WITH A FIXED POINT AND ISOTROPIC ELASTIC SUPPORT}

\author{
G. Filimonikhin \\ Doctor of Technical Sciences, Professor \\ Department of Machine Parts and Applied Mechanics** \\ E-mail: filimonikhin@yandex.ua \\ I. Fili monik hi na \\ PhD, Associate Professor* \\ E-mail: fii@online.ua \\ K. D u m e n k o \\ Doctor of Technical Sciences, Associate Professor \\ Department of Operation and Repair of Machines** \\ E-mail: dumenkokm@gmail.com \\ M. L i c h u k \\ PhD, Associate Professor* \\ E-mail: sfg_l@i.ua \\ *Department of Mathematics and Physics** \\ **Kirovograd National Technical University \\ University ave., 8, Kirovograd, Ukraine, 25006
}

in the system rotor-AB that would allow obtaining reliable analytical results at minimal labor costs.

2. Literature review and problem statement

operation, passive auto-balancers (AB) are applied [1,2]. The motion of the system rotor-AB is established in the course of time. On the so-called main (steady) motions, AB balance the rotor, while on the secondary ones - do not. From a mathematical point of view, for the occurrence of auto-balancing at a definite speed of rotation of rotor, it is necessary and sufficient that the main motions exist and they are steady, but the secondary ones do not exist or they are unstable. Therefore, the search for different steady motions of such systems, examination of conditions for their existence and stability occupy central place in the theory of $\mathrm{AB}$ [1-21].

The search for and analysis of stability of all steady motions of the system rotor- $\mathrm{AB}$ is a massive and complex mathematical problem. It is considerably complicated in such cases, relevant for practice, as: rotor balancing by $\mathrm{AB}$ with many corrector weights $(\mathrm{CW})$; when applying multi-row ball or roller $\mathrm{AB}$; rotor balancing by several $\mathrm{AB}$ in several planes of correction, etc.

Therefore, it is relevant to design effective method of determining conditions for the occurrence of auto-balancing
Let us examine certain approaches, which make it possible to simplify the process of determining conditions for the occurrence of auto-balancing.

Analytically, the search for and analysis of stability of all steady motions of the system of rotating supporting body-AB was conducted in many papers. Such studies were carried out, among others, for:

- two-ball AB, which balances a rotor that performs plane motion [1];

- multi-ball $\mathrm{AB}$, which balances a rotor within the framework of a flat model and a number of nonclassical $\mathrm{AB}$, which balance a rotor, which performs plane-parallel motion [2];

- AB with two connected CW, which balances a rotor that performs plane-parallel motion [3];

- two-ball AB, which balances in one plane of correction a rotor that performs spatial motion [4];

- two-ball AB, which balances a CD/DVD disk [5]; 
- 2-pendulum $\mathrm{AB}$, which balances a rotor on flexible shaft on elastic supports when the rotor performs plane motion [6];

- 2-pendulum AB, which balances a rotating supporting body in the isolated system [7].

The obtained results enable us to conclude that if the main motions exist and are steady, then the secondary motions, in which $\mathrm{CW}$ rotate synchronously with the rotating body, are not steady or do not exist. This result makes it possible to determine conditions for the occurrence of autobalancing by the results of studying the stability of the main motions alone. This simplified approach is widely used when studying the process of auto-balancing and is applied, in particular, in papers [8-21].

The second simplification is connected to the study of the process of auto-balancing for $\mathrm{AB}$ with two $\mathrm{CW}$ (balls, pendulums, rollers, etc). In this case, the main motions of the system rotor-AB are isolated. Simplification is achieved as the theory of stability of isolated motions is better developed than the theory of stability of one- and multi-parametric families of the steady motions.

Stability of the main motions only at rotor balancing by $\mathrm{AB}$ with two $\mathrm{CW}$ was examined in papers:

[8] - for a rotor that performs flat, spherical and spatial motion;

[9] - for a rotor on isotropic supports that performs spatial motion and that is balanced in two planes of correction;

[10] - for a rotor on anisotropic supports that performs spatial motion and that is balanced in one plane of correction;

[11] - for an elastic rotor, balanced by $\mathrm{N}$ of two-ball $\mathrm{AB}$ in $\mathrm{N}$ planes of correction;

[12] - for a rotor on isotropic supports that performs spatial motion and that is balanced in two planes of correction by two-ball AB with different balls;

[13] - for a rotor on flexible shaft on elastic supports when the rotor performs plane motion and is balanced by 2-pendulum $\mathrm{AB}$;

[14] - for a drum of a washing machine with horizontal loading;

[15] - for a disk, mounted onto a weightless flexible shaft, balanced by two two-ball AB, mounted onto the shaft from different sides from the disk;

[16] - for a rotating supporting body in the isolated system, balanced in one plane of correction by 2-pendulum AB. Let us note that this approach does not eliminate the complexity of the problem, caused by nonlinearity.

An alternative to the second simplification is the analysis of stability of the family of main motions by the minimal quantity of special parameters (generalized coordinates). This approach was realized for the first time in article [17] within the framework of a flat model of rotor with multi-ball $\mathrm{AB}$ with identical balls. Generalized coordinates of the rotor and special combinations of the angles, which determine the positions of $\mathrm{CW}$ relative to the rotor, were used as the parameters. In paper [18] the same approach is applied to a double-support rotor that performs spatial motion and is balanced by multi-ball AB. Practice simultaneously with paper [17], in article [2] they used a similar approach, only, instead of combinations of the angles, the projections of summary imbalances of the rotor and $\mathrm{AB}$ on the coordinate axes were used. During the main motions, these parameters equal zero and the process of auto-balancing may be examined by the differential equations that describe the change in these parameters. Subsequently, this method was substantially developed and it is presented in detail in paper [19]. It is essential that the differential equations, which describe the change in these parameters, are easily linearized. That is why the stability of the families of steady motions is investigated with the application of theory of stability of systems of linear differential equations with constant or periodic coefficients. Article [20] explores with the aid of this method the process of balancing an elastic rotor on two ductile supports by two multi-ball (multi-pendulum, multi-roller) AB, located near the supports.

The simplifications described above in the study of the process of auto-balancing are ineffective while rotor balancing: by several $\mathrm{AB}$ in several planes of correction, by multirow $\mathrm{AB}$, by the so-called non-classical $\mathrm{AB}$ [2] because of the complexity of $\mathrm{CW}$ moving in them. It is connected to a large number of differential equations, which describe the process of auto-balancing. The second shortcoming of these simplifications is the fact that the conditions for the occurrence of auto-balancing with their application are obtained for a particular type of $\mathrm{AB}$. For another type of $\mathrm{AB}$, it is necessary to obtain anew conditions for the occurrence of auto-balancing.

Paper [2] proposed an engineering (empirical) criterion for the occurrence of auto-balancing when balancing a rotor by one $\mathrm{AB}$ of any type in one plane of correction. In accordance with the criterion, a passive $\mathrm{AB}$ of any type will balance a rotor in the examined plane of correction when and only when, on average at one rotation of rotor, the sagging of rotor in the plane of correction from any elementary imbalance in this plane will be directed opposite to this imbalance. By applying the criterion, analytical conditions for the occurrence of auto-balancing were obtained when balancing by one $\mathrm{AB}$ of any type of rotor that performs flat, spherical, spatial motions. The obtained results coincided with the results, obtained in article [8] for the indicated rotors at their balancing by two-ball AB.

Paper [21] proposed the empirical criterion of stability of the main motion in the case of rotor balancing (both elastic and rigid) by several $\mathrm{AB}$ of particular type. Its effectiveness was demonstrated when determining stability conditions of the main motions at balancing by one or two $\mathrm{AB}$ artificial Earth satellites, stabilized by rotation. This criterion is the most effective for the analysis of stability of the main motions and their families. But there is a caveat. In the studies, the type of $\mathrm{AB}$ is considered. That is why the studies remain cumbersome while the obtained results are applicable only to a particular type of $\mathrm{AB}$.

Thus, it is relevant to modernize the empirical criterion of stability of the main motion for obtaining conditions for the occurrence of auto-balancing, suitable for any type of AB. Application of the new criterion and its efficiency is illustrated on the problem of balancing by several $\mathrm{AB}$ (excess number of $\mathrm{AB}$ ) of a solid axisymmetric rotor with the fixed point and isotropic elastic support. Such a model of rotor models extractors, centrifuges, separators, etc. The rotors of such machines can be loaded with a large amount of the treated raw material, which creates large imbalances. For the increase in the summary balancing capacitance of $\mathrm{AB}$ without increasing their overall dimensions, it is expedient to balance such rotors by several $\mathrm{AB}$, located in parallel. The conditions for the occurrence of auto-balancing for this problem have not been obtained as yet.

\section{Aim and tasks of the study}

The purpose of this work is to formulate the empirical criterion for the occurrence of auto-balancing for a rotor 
with several passive $\mathrm{AB}$ and to illustrate its application on the rotor with a fixed point.

To accomplish the set aim, it is necessary to solve the following tasks of the study:

- to formulate a criterion for the occurrence of auto-balancing when balancing a rigid or elastic rotor by several passive $\mathrm{AB}$ of any type;

- to establish a general sequence of applying the criterion and the results, obtained with its help;

- by applying the criterion, to obtain conditions for the occurrence of auto-balancing when balancing a rotor with a fixed point by several $\mathrm{AB}$ of any type.

\section{Method of constructing the empirical criterion for the occurrence of auto-balancing for the case of several $\mathrm{AB}$}

Any passive $\mathrm{AB}$ are considered:

- classical - ball, roller, pendulum, circular, liquid, etc.;

- non-classical - in which CW of special form have a fixed point on the longitudinal axis of a rotor and the centers of masses of CW move not by the circles whose planes are perpendicular to the longitudinal axis of the rotor.

The empirical (engineering) criterion of stability of the main motion is being modernized. The criterion is formulated in paper [21] as follows.

Let us assume that $\mathrm{n}$ passive $\mathrm{AB}$ with solid $\mathrm{CW}$ of particular type are mounted on the rotor for the balancing in $\mathrm{n}$ different planes of correction. The stability of a particular main motion is examined (both isolated and belonging to one- or multi-parametric family). Let us fix the positions of $\mathrm{CW}$ in $\mathrm{AB}$ in this main motion. Then for its stability, it is necessary and sufficient that at any elementary imbalances $\overrightarrow{\mathrm{s}}_{\mathrm{j}}$, which are in the $j$-th planes of correction and applied at points $j$ on the longitudinal axis of the rotor, the condition is satisfied

$$
f\left(\vec{s}_{1}, \ldots, \vec{S}_{n}\right)=\frac{1}{T} \int_{0}^{T}\left(\sum_{j=1}^{n} \vec{s}_{j}(t) \cdot \vec{r}_{j}(t)\right) d t<0
$$

where $t$ is the time; $\vec{r}_{j}$ is the vector of deviation of the point $\mathrm{j}$ from its position in the main motion, caused by the elementary imbalances $\overrightarrow{\mathrm{s}}_{1}, \ldots, \overrightarrow{\mathrm{s}}_{\mathrm{n}}$; T is the period in case the motion is periodic or another characteristic time interval (time of one or several rotations of rotor, time interval considerably larger than 1, etc.).

The elementary imbalance $\vec{s}_{j}$ lies in the $j$-th plane of correction and is formed by elementary mass, located at a distance from the longitudinal axis of the rotor, considerably larger than the deviation of the point $\mathrm{j}$ from its position in the main motion.

The criterion is applicable both for the rigid and elastic rotors on ductile supports and elastic rotors on the rigid supports.

A deficiency of the criterion lies in the fact that in it does not take into account the type of $\mathrm{AB}$. That is why the computations are bulky while the obtained results have private character. For obtaining the most general results, when formulating the criterion, it is necessary to disregard the components, added by AB.

The appropriate components of the theory of rotor machines are used while applying the criterion to particular rotors.
5. Results of constructing the empirical criterion for the occurrence of auto-balancing for the case of several AB

\section{1. The types of $A B$ fit for the criterion}

The criterion is built for passive $\mathrm{AB}$ with solid $\mathrm{CW}-$ classical and non-classical.

The classical AB are circular, ball, roller, pendulum [1,2]. Their CW have the appropriate form - Fig. 1.

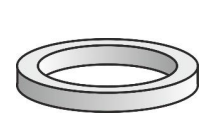

$a$

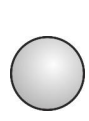

b

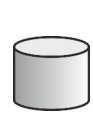

C

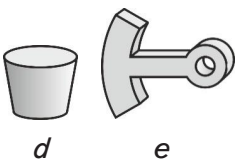

e
Fig. 1. CW of classical $A B$ with solid CW: $a-$ ring; $b$ - sphere; $c$ - cylindrical roller, $d$-conical; $e-$ pendulum

The centers of masses of such CW move relative to a rotor by the circles whose centers are on the longitudinal axis of the rotor and the planes of which are perpendicular to this axis (Fig. 2)

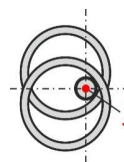

$a$

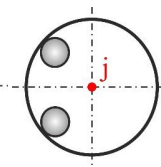

b

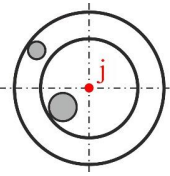

c

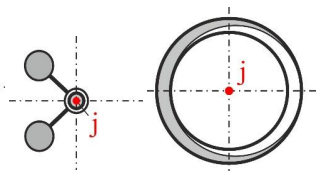

d e
Fig. 2. Classical AB: $a$ - circular; $b$ - ball (roller), single-row, $c-$ two-row; $d$ - pendulum; $e$ - liquid

The plane, in which the centers of CW masses move, is the plane of correction of $\mathrm{AB}$. The point $\mathrm{j}$ lies on the longitudinal axis of the rotor and the centers of $\mathrm{CW}$ masses move by circles around this point in the plane of correction.

Classical AB include liquid AB (Fig. 2,e) [1, 2]. In contrast to $\mathrm{AB}$ with solid $\mathrm{CW}$, such $\mathrm{AB}$ cannot fully balance the rotor in their plane of correction.

In non-classical AB [2], CW have a special form (Fig. 3).

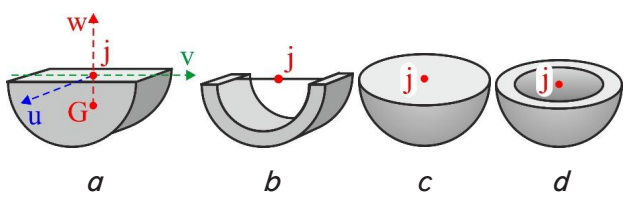

Fig. 3. Non-classical CW - for which the axial moments of inertia relative to the principal axes, passing through the suspension point $\mathrm{j}$, are such as: $a, b-\mathrm{J}_{\mathrm{v}}=\mathrm{J}_{\mathrm{w}} \neq \mathrm{J}_{\mathrm{u}} ; c, d-\mathrm{J}_{\mathrm{u}}=\mathrm{J}_{\mathrm{v}}=\mathrm{J}_{\mathrm{w}}$

They perform particular motion around the point $\mathrm{j}$ on the longitudinal axis w of the rotor, which is not the rotation around this axis (Fig. 4).

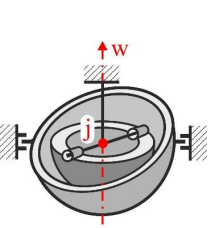

a

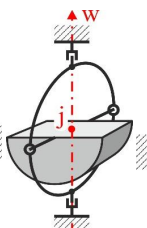

b

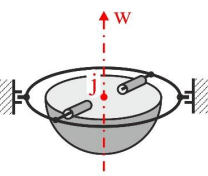

c

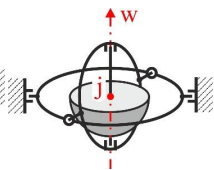

d
Fig. 4. Non-classical $A B$ - in which $C W$ rotate around: $a-$ transverse axes of rotor; $b-$ longitudinal (w) and transverse axes of rotor; $c-$ two axes that are not longitudinal; $d$ - point (j) on the longitudinal axis ( $w$ ) of the rotor 
It is assumed that a rotor is balanced in $\mathrm{n}$ planes of correction by $n$ passive $\mathrm{AB}$ of any type, both with solid $\mathrm{CW}$ and liquid $\mathrm{AB}$.

\section{2. Empirical criterion for the occurrence of auto-} balancing

We will assume that the masses of $\mathrm{AB}$ and $\mathrm{CW}$ are considerably less than the mass of a rotor. Then $\mathrm{AB}$ and $\mathrm{CW}$ change insignificantly the mass-inertia characteristics of a rotor. Taking this into account, let us formulate the following empirical criterion for the occurrence of auto-balancing.

Assume that for the balancing, $\mathrm{n}$ passive $\mathrm{AB}$ of any type in $n$ different planes of corrections are mounted onto a rotor. Then, for the occurrence of auto-balancing, it is necessary and sufficient that at any elementary imbalances $\overrightarrow{\mathrm{s}}_{\mathrm{j}}$, which are in the $j$-th planes of correction and applied at the appropriate points $\mathrm{j}$ on the longitudinal axis of the rotor, the condition is satisfied

$$
f\left(\vec{s}_{1}, \ldots, \vec{s}_{n}\right)=\frac{1}{T} \int_{0}^{T}\left(\sum_{j=1}^{n} \vec{s}_{j}(t) \cdot \vec{r}_{j}(t)\right) d t<0,
$$

where $t$ is the time; $\vec{r}_{j}$ is the vector of deviation of the point $j$ from its position in a motionless rotor, caused by the elementary imbalances $\overrightarrow{\mathrm{s}}_{1}, \ldots, \overrightarrow{\mathrm{s}}_{\mathrm{n}}$; T is the period in case the motion is periodic or another characteristic time interval (time of one or several rotations of rotor, time interval considerably larger than 1, etc.).

Let us note that a mathematical record of the empirical criterion for the occurrence of auto-balancing (2) completely coincides with the mathematical record of the empirical criterion of stability of the main motion (1). The difference between the criteria consists in the method of determining the vectors $\vec{r}_{j}$ of deviations of the points $j$.

\section{3. The order of application of the criterion and ob-} tained results

The criterion is intended to answer the question - is it possible in principle, and under what conditions, to automatically balance a particular rotor $n$ by passive $A B$ of any type in $\mathrm{n}$ planes of correction. The criterion is applied in the following sequence:

1) a physical-mechanical model of a rotor with elementary imbalances, applied in the future suspension points of $\mathrm{AB}$, is described;

2) differential equations of motion of the unbalanced rotor are derived;

3) steady motion of a rotor, which corresponds to the applied elementary imbalances, is searched for as a particular solution of the heterogeneous system of equations of motion;

4) a functional of the criterion for the occurrence of auto-balancing is built;

5) conditions for the occurrence of auto-balancing are determined from the condition of negativity of the functional.

Let us note that, as a rule, the functional of the criterion is quadratic form from the elementary imbalances. The negative certainty of this form can be investigated by using the Sylvester criterion. The result is the conditions of two types. The first ones assign limitations to the mass-inertia characteristics of a rotor. The second ones are the range of angular rates of rotation of the rotor, on which auto-balancing will occur provided the first conditions are satisfied.
5. 4. Example of application of the criterion to a rotor with a fixed point

5.4.1. Description of physical-mechanical model of the rotor

Fig. 5, $a$ demonstrates a schematic of the rotor with the points of application of elementary imbalances to longitudinal axis of the rotor. Fig. 5, $b$ displays kinematics of motion of the rotor. Fig. 5, $d$ presents kinematics of motion of the elementary imbalance $\vec{s}_{j}$, which is in the j-th plane of correction.
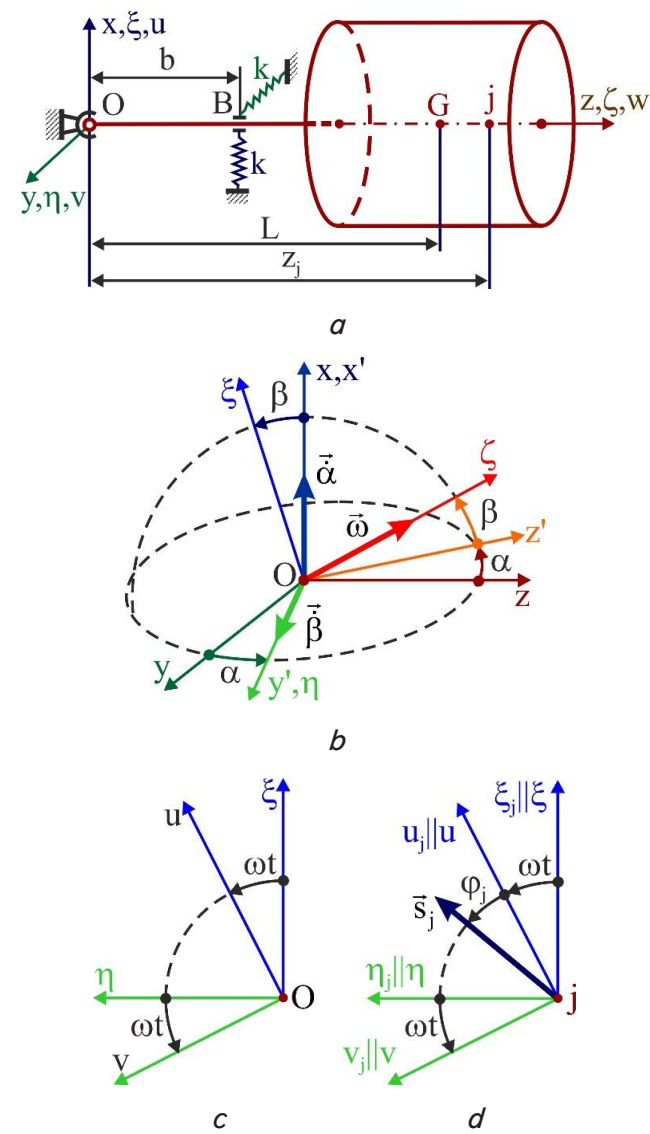

Fig. 5. Model of unbalanced rotor with a fixed point: $a$ - schematic of rotor with the points of application of elementary imbalances to longitudinal axis of the rotor; $b$ - turnings of rotor around the point $O$ by the Resal's angles $\alpha, \beta ; c-$ turning of rotor around longitudinal axis by the angle $\omega \mathrm{t} ; d-$ kinematics of motion of the elementary imbalance $\overrightarrow{\mathrm{s}}_{\mathrm{j}}$

In Fig. 5, $a$, the Oxyz axes are motionless, axis $\mathrm{z}$ is directed along longitudinal axis of the rotor in the absence of its displacement, and axes $\mathrm{x}, \mathrm{y}-$ in such a way that the coordinate system is right-hand.

The $\mathrm{O} \xi \eta \zeta$ axes originally coincide with the motionless axes Oxyz. In the process of motion, rotor at first is turned by two Resal's angles $\alpha, \beta$ (Fig. $5, b$ ). In this case

$$
\mathrm{Oxyz} \stackrel{\alpha}{\longrightarrow} \mathrm{Ox}^{\prime} \mathrm{y}^{\prime} \mathrm{z}^{\prime} \stackrel{\beta}{\longrightarrow} \mathrm{O} \xi \eta \zeta .
$$

Then the rotor is turned around its longitudinal axis $\zeta$ (Fig. $5, c$ ) by the angle $\omega$ t, where $\omega$ is the constant angular rate of rotation of rotor around the axis $\zeta$. In this case, the $\mathrm{O} \xi \eta \zeta$ axes pass into the Ouvw axes, rigidly connected with the rotor. 
It is assumed that the rotor is axisymmetric. Then the axial moments of inertia of the rotor relative to the principal central axes $\xi_{\mathrm{G}}, \eta_{\mathrm{G}}, \zeta_{\mathrm{G}}$, which are parallel to the axes $\xi, \eta, \zeta$ (and the axes $\mathrm{u}_{\mathrm{G}}, \mathrm{v}_{\mathrm{G}}, \mathrm{w}_{\mathrm{G}}$, which are parallel to the $\mathrm{u}, \mathrm{v}, \mathrm{w}$ axes) are equal to A, A, C, respectively.

Angular velocity vector of rotation of the rotor

$$
\vec{\Omega}=\vec{\omega}+\dot{\vec{\alpha}}+\dot{\vec{\beta}}
$$

In the projections onto the coordinate axes $\mathrm{O} \xi \eta \zeta:$

$$
\Omega_{\xi}=\dot{\alpha} \cos \beta, \quad \Omega_{\eta}=\dot{\beta}, \quad \Omega_{\zeta}=\omega+\dot{\alpha} \sin \beta .
$$

With an accuracy to magnitudes of first-order of smallness inclusively

$$
\Omega_{\xi} \approx \dot{\alpha}, \quad \Omega_{\eta} \approx \dot{\beta}, \quad \Omega_{\zeta} \approx \omega .
$$

According to Huygens theorem, the axial moments of inertia of rotor relative to the $\mathrm{O} \xi \eta \zeta$ axes:

$$
\mathrm{C}_{\zeta}=\mathrm{C}, \mathrm{A}_{\xi}=\mathrm{A}_{\eta}=\mathrm{A}+\mathrm{ML}^{2}
$$

where $\mathrm{L}$ is the distance from the center of masses of the rotor to the axes $\xi$, $\eta$. Here symmetry of the rotor is taken into account, due to which rotation of the rotor around the axis $\zeta$ does not change the axial moments of inertia $A_{\xi}, A_{\eta}$.

\section{4. 2. Differential equations of motion of the rotor}

For the Resal's small angles, kinetic moment of the rotor relative to the point $\mathrm{O}$, decomposed into components, directed along the coordinate axes $\mathrm{O} \xi \eta \zeta$, takes the form [2]:

$$
\overrightarrow{\mathrm{K}}_{\mathrm{C}}=\overrightarrow{\mathrm{i}} \mathrm{A}_{\xi} \dot{\alpha}+\overrightarrow{\mathrm{j}} \mathrm{A}_{\xi} \dot{\beta}+\overrightarrow{\mathrm{k}} \mathrm{C} \omega,
$$

where $\vec{i}, \vec{j}, \vec{k}$ are the unit vectors, directed along the coordinate axes $\xi, \eta, \zeta$, respectively. Then the theorem on the change in the moment of amount of material system relative to the motionless point $\mathrm{O}$ takes the form [2]:

$$
\frac{\mathrm{d}^{\prime} \overrightarrow{\mathrm{K}}_{\mathrm{C}}}{\mathrm{dt}}+\vec{\Omega}_{\mathrm{O} \xi \eta \zeta} \times \overrightarrow{\mathrm{K}}_{\mathrm{C}}=\overrightarrow{\mathrm{M}}_{\mathrm{O}}^{(\mathrm{ext})},
$$

where $d^{\prime}(\cdot) / d t$ is the local time derivative in the rotating coordinate system $\mathrm{O} \xi \eta \zeta ; \overrightarrow{\mathrm{M}}_{\mathrm{O}}^{\text {(ext) }}$ is the main moment of external forces, which act on the rotor, found relative to the point $\mathrm{O}$

$$
\vec{\Omega}_{\mathrm{O} \xi \eta \zeta} \approx(\dot{\alpha}, \dot{\beta}, 0)^{\mathrm{T}}
$$

- angular rate of rotation of the coordinate system $\mathrm{O} \xi \eta \zeta$, found in the projections onto the $\xi, \eta, \zeta$ axes.

With accuracy to magnitudes of first-order of smallness, in the projections onto the axes $\xi, \eta$, theorem (7) gives the following two differential equations of motion of the rotor:

$$
\begin{aligned}
& A_{\xi} \ddot{\alpha}+C \omega \dot{\beta}=M_{\xi}^{(e x t)}, \\
& A_{\xi} \ddot{\beta}-C \omega \dot{\alpha}=M_{\eta}^{(e x t)},
\end{aligned}
$$

where $\mathbf{M}_{\xi}^{(\text {ext) }}, \mathbf{M}_{\eta}^{(\text {ext) }}$ are the main moments of external forces, which act on the rotor, found relative to the $\xi, \eta$ axes. Because of smallness of the imbalances, we consider that they do not influence the mass and axial moments of inertia of the rotor. We consider that their action is manifested only through centrifugal forces of inertia.

The external forces and moments, which act on the rotor, are formed by elastic forces and centrifugal forces from the imbalances. At the Resal's small angles, the projections onto the moving axes $\xi, \eta$ of the forces and moments, caused by imbalances, are approximately determined as follows:

$$
\begin{aligned}
& F_{j \xi}^{(s)}=s_{j} \omega^{2} \cos \left(\omega t+\phi_{j}\right), \\
& F_{j \eta}^{(s)}=s_{j} \omega^{2} \sin \left(\omega t+\phi_{j}\right), \\
& M_{j \xi}^{(s)}=-F_{j \eta}^{(s)} z_{j}=-s_{j} Z_{j} \omega^{2} \sin \left(\omega t+\phi_{j}\right), \\
& M_{j \eta}^{(s)}=F_{j \xi}^{(s)} z_{j}=s_{j} z_{j} \omega^{2} \cos \left(\omega t+\phi_{j}\right) .
\end{aligned}
$$

At the Resal's small angles, the projections onto the moving axes $\xi, \eta$ of the forces and moments, caused by elastic forces, are approximately determined as follows:

$$
\begin{aligned}
& \mathrm{F}_{\mathrm{B} \xi}^{(\mathrm{k})}=-\mathrm{kb} \beta, \mathrm{F}_{\mathrm{B \eta}}^{(\mathrm{k})}=\mathrm{kb} \alpha, \\
& \mathrm{M}_{\xi}^{(\mathrm{k})}=-\mathrm{kb}^{2} \alpha, \mathrm{M}_{\eta}^{(\mathrm{k})}=-\mathrm{kb}^{2} \beta .
\end{aligned}
$$

From which we find

$$
\begin{aligned}
& \mathrm{M}_{\xi}^{(\text {ext })}=\sum_{j=1}^{\mathrm{n}} \mathrm{M}_{\mathrm{j} \xi}^{(\mathrm{s})}+\mathrm{M}_{\xi}^{(\mathrm{k})}= \\
& =-\sum_{\mathrm{j}=1}^{\mathrm{n}} \mathrm{s}_{\mathrm{j}} \mathrm{Z}_{\mathrm{j}} \omega^{2} \sin \left(\omega \mathrm{t}+\phi_{\mathrm{j}}\right)-\mathrm{k} \mathrm{b}^{2} \alpha ; \\
& \mathrm{M}_{\eta}^{(\mathrm{ext})}=\sum_{\mathrm{j}=1}^{\mathrm{n}} \mathrm{M}_{\mathrm{j} \eta}^{(\mathrm{s})}+\mathrm{M}_{\eta}^{(\mathrm{k})}= \\
& =\sum_{\mathrm{j}=1}^{\mathrm{n}} \mathrm{s}_{\mathrm{j}} \mathrm{Z}_{\mathrm{j}} \omega^{2} \cos \left(\omega \mathrm{t}+\phi_{\mathrm{j}}\right)-\mathrm{kb}^{2} \beta .
\end{aligned}
$$

Substituting this to (9), we obtain the following differential equations of motion of the unbalanced rotor

$$
\begin{aligned}
& A_{\xi} \ddot{\alpha}+C \omega \dot{\beta}+k^{2} \alpha=-\omega^{2} \sum_{j=1}^{n} s_{j} z_{j} \sin \left(\omega t+\phi_{j}\right), \\
& A_{\xi} \ddot{\beta}-C \omega \dot{\alpha}+k^{2} \beta=\omega^{2} \sum_{j=1}^{n} s_{j} z_{j} \cos \left(\omega t+\phi_{j}\right) .
\end{aligned}
$$

Let us introduce comprehensive variable

$$
\psi=\alpha+i \beta .
$$

Let us multiply the second equation in (13) by the imaginary unit $\mathrm{i}$ and add to the first one. We will obtain the following differential equation of motion of the rotor in the complex form

$$
\mathrm{A}_{\xi} \ddot{\psi}-\mathrm{iC} \omega \dot{\psi}+\mathrm{kb}^{2} \psi=i \omega^{2} \mathrm{e}^{\mathrm{i} \omega t} \sum_{\mathrm{j}=1}^{\mathrm{n}} \mathrm{s}_{\mathrm{j}} \mathrm{Z}_{\mathrm{j}} \mathrm{e}^{\mathrm{i} \phi_{\mathrm{j}}} .
$$

Let us denote

$$
I=\sum_{j=1}^{n} S_{j} Z_{j} e^{i \phi_{j}} .
$$

Then differential equation of motion of the rotor will take the form

$$
\mathrm{A}_{\xi} \ddot{\psi}-\mathrm{iC} \omega \dot{\psi}+\mathrm{kb}^{2} \psi=i \omega^{2} \mathrm{Ie} \mathrm{e}^{\mathrm{i} \omega t} .
$$

Let us note

$$
I_{u w}=\operatorname{Re} I=\sum_{j=1}^{n} s_{j} z_{j} \cos \phi_{j},
$$




$$
I_{v w}=\operatorname{Re} I=\sum_{j=1}^{n} s_{j} z_{j} \sin \phi_{j} ;
$$

- product of inertia of the rotor, which determine its moment imbalance.

\section{4. 3. Steady motion of the rotor, which corresponds} to the applied elementary imbalances

We search for a particular solution of differential equation (16) in the form

$$
\psi=\mathrm{De}^{\mathrm{i} \omega \mathrm{t}} .
$$

Substitution (18) into (16), after reductions by $\mathrm{e}^{\mathrm{i} \omega t}$, will produce the following algebraic equation for determining D:

$$
\left[\mathrm{kb} \mathrm{b}^{2}-\left(\mathrm{A}_{\xi}-\mathrm{C}\right) \omega^{2}\right] \mathrm{D}=\mathrm{iI} \omega^{2}
$$

Solution of equation (19) takes the form

$$
\mathrm{D}=\mathrm{i} I \omega^{2} /\left[\mathrm{kb}^{2}-\left(\mathrm{A}_{\xi}-\mathrm{C}\right) \omega^{2}\right] .
$$

Then the particular solution (18) of differential equation (16) takes the form

$$
\psi=\mathrm{i} I \omega^{2} \mathrm{e}^{\mathrm{i} \omega t} /\left[\mathrm{kb} \mathrm{b}^{2}-\left(\mathrm{A}_{\xi}-\mathrm{C}\right) \omega^{2}\right]
$$

\section{4. 4. Construction of functional of the criterion}

Displacements of the points $j$ in the planes of correction assign coordinates:

$$
x_{j}=\beta z_{j}, \quad y_{j}=-\alpha z_{j} .
$$

Let us introduce comprehensive displacements of the points $\mathrm{j}$

$$
\begin{aligned}
& \mathbf{r}_{j}=x_{j}+i y_{j}=\beta z_{j}-i \alpha z_{j}=-i z_{j}(\alpha+i \beta)=-i z_{j} \psi= \\
& =z_{j} \omega \omega^{2} e^{i \omega t} /\left[k b^{2}-\left(A_{\xi}-C\right) \omega^{2}\right] .
\end{aligned}
$$

Projections onto the axes $\mathrm{x}, \mathrm{y}$ of vector of the $\mathrm{j}$-th elementary imbalance:

$$
s_{j x}=s_{j} \cos \left(\omega t+\phi_{j}\right), \quad s_{j y}=s_{j} \sin \left(\omega t+\phi_{j}\right) .
$$

Let us introduce comprehensive representation of the imbalance

$$
\begin{aligned}
& \mathbf{s}_{\mathrm{j}}=\mathrm{s}_{\mathrm{jx}}+\mathrm{is}_{\mathrm{jy}}=\mathrm{s}_{\mathrm{j}} \cos \left(\omega \mathrm{t}+\phi_{\mathrm{j}}\right)+ \\
& +\mathrm{is} \mathrm{s}_{\mathrm{j}} \sin \left(\omega \mathrm{t}+\phi_{\mathrm{j}}\right)=\mathrm{s}_{\mathrm{j}} \mathrm{e}^{\mathrm{i}\left(\omega t+\phi_{\mathrm{j}}\right)} .
\end{aligned}
$$
form:

The integrand expression of functional (2) will take the

$$
\begin{aligned}
& \sum_{j=1}^{n} \vec{s}_{j}(t) \cdot \vec{r}_{j}(t)=\sum_{j=1}^{n}\left(s_{j} \bar{r}_{j}+\bar{s}_{j} r_{j}\right) / 2= \\
& =\frac{\omega^{2}}{k b^{2}-\left(A_{\xi}-C\right) \omega^{2}} \sum_{j=1}^{n}\left[s_{j} e^{i\left(\omega t+\phi_{j}\right)} \bar{I} z_{j} e^{-i \omega t}+s_{j} e^{-i\left(\omega t+\phi_{j}\right)} I z_{j} e^{i \omega t}\right] / 2= \\
& =\frac{1}{2} \cdot \frac{\omega^{2}}{k b^{2}-\left(A_{\xi}-C\right) \omega^{2}}\left[\bar{I} \sum_{j=1}^{n} s_{j} z_{j} e^{i \phi_{j}}+I \sum_{j=1}^{n} s_{j} z_{j} e^{-i \phi_{j}}\right]= \\
& =\frac{\omega^{2}}{k b^{2}-\left(A_{\xi}-C\right) \omega^{2}} I \bar{I}=\frac{\omega^{2}\left(I_{u w}^{2}+I_{v w}^{2}\right)}{k b^{2}-\left(A_{\xi}-C\right) \omega^{2}} .
\end{aligned}
$$

Then the functional and the criterion of the occurrence of auto-balancing (2) will take the form:

$$
\begin{aligned}
& f\left(\mathbf{s}_{1}, \ldots, \mathbf{s}_{\mathrm{n}}\right)=\frac{\omega}{2 \pi} \int_{0}^{2 \pi / \omega}\left(\sum_{\mathrm{i}=1}^{\mathrm{n}} \mathbf{s}_{\mathrm{j}}(\mathrm{t}) \cdot \mathbf{r}_{\mathrm{j}}(\mathrm{t})\right) \mathrm{dt}= \\
& =\frac{\omega^{2}\left(\mathrm{I}_{\mathrm{uW}}^{2}+\mathrm{I}_{\mathrm{vW}}^{2}\right)}{\mathrm{kb}^{2}-\left(\mathrm{A}_{\xi}-\mathrm{C}\right) \omega^{2}}<0,
\end{aligned}
$$

where the time of one rotation of the rotor $(T=2 \pi / \omega)$ is accepted as the characteristic time interval.

5. 4. 5. Determining conditions for the occurrence of auto-balancing

Let us introduce resonance speed into examination

$$
\omega_{1}=\sqrt{\mathrm{kb}^{2} /\left(\mathrm{A}_{\xi}-\mathrm{C}\right)} .
$$

This speed exists only in the case of a long rotor, relative to the point $\mathrm{O}$

$$
\mathrm{A}_{\xi}>\mathrm{C} \text {. }
$$

Condition (27) will be satisfied (and auto-balancing will occur) only in the case of a long rotor, relative to the point $\mathrm{O}$, at critical resonant speeds of rotation of the rotor

$$
\omega>\omega_{1}
$$

Analogous result for the case of rotor balancing with a fixed point by one two-ball $\mathrm{AB}$ was obtained in paper [8] by the composition of differential equations of motion of the system rotor-AB, by defining the main motion, exploration of its stability.

\section{Discussion of the obtained criterion and conditions for the occurrence of auto-balancing for a rotor with a fixed point}

The empirical criterion for the occurrence of auto-balancing makes it possible to obtain universal conditions for the occurrence of auto-balancing, applicable for any type of $\mathrm{AB}$. In this case, to answer the question about possibility of auto-balancing of a rotor by passive $\mathrm{AB}$, the existing mathematical model of a rotor without $\mathrm{AB}$ is sufficient. This considerably simplifies computations and reduces the labor intensity of studies.

The empirical criterion for the occurrence of auto-balancing enables us to solve the problem of determining conditions for the occurrence of auto-balancing in "zero approximation". It is due to the fact that the formulation of the criterion does not take into account the types and masses of AB. That is why, in "zero approximation", the possibility of applying passive AB for rotor balancing is determined not by the types of $\mathrm{AB}$, but by rotor itself.

It is obvious that the more precise conditions for the occurrence of auto-balancing (in the "first approximation") may be obtained by the empirical criterion of stability of the main motion, formulated in paper [21]. This criterion takes into account both the type and masses of $\mathrm{AB}$ and the position of $\mathrm{CW}$, in the considered main motion. In this case, the higher accuracy of solution of the problem is achieved by the larger labor intensity of mathematical calculations and transformations. 
In the case of rotor with a motionless point and isotropic elastic support, auto-balancing is possible only in the case of a long rotor, relative to the point $\mathrm{O}$. There may be any number of $\mathrm{AB}$ (planes of correction). Auto-balancing starts at the speeds, which exceed the only resonance speed of rotation of the rotor. This is the first result, obtained for the case of $\mathrm{AB}$ excess.

In future it is planned to obtain, with the help of the developed empirical criterion, conditions for the occurrence of auto-balancing for a rotor that performs spatial motion and for elastic rotor, balanced by several $\mathrm{AB}$ of any type in several planes of correction. We plan to compare results, obtained with the use of the empirical criterion, with the known results, obtained by other methods.

\section{Conclusions}

1. In accordance with the empirical criterion for the occurrence of auto-balancing, the possibility of applying passive AB for rotor balancing (in "zero approximation") is determined not by the type of $\mathrm{AB}$, but by rotor itself. In this case, reaction of rotor to the elementary imbalances, applied in the required planes of correction, is essential. That is why the criterion makes it possible to obtain universal conditions for the occurrence of auto-balancing, applied for any types of AB.

2 . The conditions obtained with the help of the criterion are divided into two groups:

- conditions, assigned on the mass-inertia characteristics of rotor;

- ranges of angular speeds of rotation of rotor, at which auto-balancing will occur provided the first group of conditions is met.

3. In the case of axisymmetric rotor with a fixed point and isotropic elastic support, auto-balancing will occur only in the case of a long rotor, relative to the point $\mathrm{O}$, independent of the number of $\mathrm{AB}$ (planes of correction) at speeds that exceed the only resonance speed of rotor rotation.

\section{References}

1. Thearle, E. L. Automatic dynamic balancers Part 2 - Ring, pendulum and ball balancers [Text] / E. L. Thearle // Machine Design. 1950. - Vol. 22, Issue 10. - P. 103-106.

2. Filimonihin, G. B. Zrivnovazhennja i vibrozahyst rotoriv avtobalansyramy z tverdymy koryguval'nymy vantazhamy [Balancing and protection from vibrations of rotors by autobalancers with rigid corrective weights] [Text] / G. B. Filimonihin. - Kirovograd: KNTU, 2004. - 352 p.

3. Filimonikhin, G. B. Balancing a Rotor with Two Coupled Perfectly Rigid Bodies [Text] / G. B. Filimonikhin, Yu. A. Nevdakha // International Applied Mechanics. - 2002. - Vol. 38, Issue 3. - P. 377-386. doi: 10.1023/a:1016050732065

4. Sperling, L. Single-Plain Auto-Balancing of Rigid Rotors [Text] / L. Sperling, B. Ryzhik, H. Duckstein // Technische Mechanik. 2004, - Vol. 24, Issue 1. - P. 1-24. - Available at: http://141.44.1.20/ifme/zeitschrift_tm/2004_Heft1/sperling.pdf

5. Lu, C.-J. Analytical study of the stability of a two-ball automatic balancer [Text] / C.-J. Lu, M.-C. Wang, S.-H. Huang // Mechanical Systems and Signal Processing. - 2009. - Vol. 23, Issue 3. - P. 884-896. doi: 10.1016/j.ymssp.2008.06.008

6. Dubovik, V. A. Statsionarnyie dvizheniya mayatnikovogo avtobalansira na gibkom valu s uprugimi oporami [Text] / V. A. Dubovik, G. R. Ziyakaev // Avtomatizatsiya. Sovremennyie tehnologii. - 2012. - Vol. 2. - P. 3-7.

7. Filimonikhin, G. B. Stability of Steady-State Motion of an Isolated System Consisting of a Rotating Body and Two Pendulums [Text] / G. B. Filimonikhin, I. I. Filimonikhina, V. V. Pirogov // International Applied Mechanics. - 2014. - Vol. 50, Issue 4. P. 459-469. doi: 10.1007/s10778-014-0651-9

8. Nesterenko, V. Avtomaticheskaja balansirovka rotorov priborov i mashin so mnogimi stepenjami svobody [Automatic rotor balancing devices and machines with many degrees of freedom] [Text] / V. Nesterenko. - Tomsk, Izd-vo Tomsk. un-ta, 1985. -84 p.

9. Sperling, L. Two-plain automatic balancing [Text] / L. Sperling, B. Ryzhik, H. Duckstein // Machine Dynamics Problems. - 2001. Vol. 25, Issue 3/4. - P. 139-152.

10. Sperling, L. Auto-Balancing of Anisotropically Supported Rigid Rotors [Text] / L. Sperling, B. Ryzhik, H. Duckstein // Technische Mechanik. - 2004. - Vol. 24, Issue 1, - P. 37-50. - Available at: http://141.44.1.20/ifme/zeitschrift_tm/2004_Heft1/ryzhik_autobalancing.pdf

11. Ehyaei, J. Dynamic Response and Stability Analysis of an Unbalanced Flexible Rotating Shaft Equipped with N Automatic Ball-Balancers [Text] / J. Ehyaei, M. M. Moghaddam // Journal of Sound and Vibration. - 2009. - Vol. 321, Issue 3-5. -P. $554-571$. doi: $10.1016 /$ j.jsv.2008.10.019

12. Rodrigues, D. J. Two-plane automatic balancing: A symmetry breaking analysis [Text] / D. J. Rodrigues, A. R. Champneys, M. I. Friswell, R. E. Wilson // International Journal of Non-Linear Mechanics. - 2011. - Vol. 46, Issue 9. - P. 1139-1154. doi: 10.1016/j.ijnonlinmec.2011.04.033

13. Dubovik, V. A. Osnovnoe dvizhenie dvuhmayatnikovogo avtobalansira na gibkom valu s uprugimi oporami [Main movement of two pendulum device at flexible shaft with elastic supports] [Text] / V. A. Dubovik, G. R. Ziyakaev // Bulletin of the Tomsk Polytechnic University: Mathematics and Mechanics. Physics. - 2010. - Vol. 317, Issue 2. - P. 37-39. - Available at: http:// www.lib.tpu.ru/fulltext/v/Bulletin_TPU/2010/v317/i2/08.pdf 
14. Chen, H.-W. Stability and dynamic analyses of a horizontal axis washing machine with a ball balancer [Text] / H.-W. Chen, Q.-J. Zhang, X.-Q. Wu // Mechanism and Machine Theory. - 2015. - Vol. 87. - P. 131-149. doi: 10.1016/j.mechmachtheory.2015.01.001

15. Majewski, T. Self-balancing system of the disk on an elastic shaft [Text] / T. Majewski, D. Szwedowicz, M. A. M. Melo // Journal of Sound and Vibration. - 2015. - Vol. 359. - P. 2-20. doi: 10.1016/j.jsv.2015.06.035

16. Pirogov, V. Investigation of the process of stabilization of the rotational axis of the lifting body by the pendulum autobalancer [Text] / V. Pirogov // Eastern-European Journal of Enterprise Technologies. - 2016. - Vol. 2, Issue 7 (80). - P. 49-63. doi: 10.15587/1729-4061.2016.63955

17. Gorbenko, A. N. On the Stability of Self-Balancing of a Rotor with the Help of Balls [Text] / A. N. Gorbenko // Strength of Materials. - 2003. - Vol. 35, Issue 3. - P. 305-312. doi: 10.1023/a:1024621023821

18. Gorbenko, A. Mass-Inertial Characteristics and Dimensionless Equations of Two-bearing Rotor Motion with Auto-balancer in Terms of Compensating Body Mass [Text] / A. Gorbenko // Science and Education of the Bauman MSTU. - 2014. - Vol. 15, Issue 12. - P. 266-294. doi: 10.7463/1215.0827773

19. Filimonikhin, G. B. Vid i struktura differentsialnykh uravneniy dvizheniya i protsessa uravnoveshivaniya rotornoy mashiny s avtobalansirami [Form and structure of differential equations of motion and process of auto-balancing in the rotor machine with auto-balancers] [Text] / G. B. Filimonikhin, V. V. Goncharov // Bulletin of the Tomsk Polytechnic University. Geo Assets Engineering. - 2015. - Vol. 326, Issue 12. - P. 20-30. - Available at: http://www.lib.tpu.ru/fulltext/v/Bulletin_TPU/2015/v326/ i12/02.pdf

20. Goncharov, V. Studying the peculiarities of balancing of flexible double-support rotors by two passive automatic balancers placed near supports [Text] / V. Goncharov, G. Filimonikhin, K. Dumenko, M. Lychuk // Eastern-European Journal of Enterprise Technologies. - 2016. - Vol. 4, Issue 7(82). - P. 4-9. doi: 10.15587/1729-4061.2016.75115

21. Filimonikhina, I. I. Conditions for balancing a rotating body in an isolated system with automatic balancers [Text] / I. I. Filimonikhina, G. B. Filimonikhin // International Applied Mechanics. - 2007. - Vol. 43, Issue 11. - P.1276-1282. doi: 10.1007/s10778007-0132-5 